\title{
Rostrofacial Indices of the Nigerian Local Dog: Implications in Veterinary Oral and Maxillo-facial Anaesthesiology of the Dolichocephalic Canine Breed
}

\author{
Índice Rostrofacial del Perro Local Nigeriano: Implicancias en Anestesiología Oral \\ y Maxilofacial Veterinaria de la Raza Canina Dolicocéfala
}

\author{
Olumayowa Olawumi Igado*
}

\begin{abstract}
IGADO, O. O. Rostrofacial indices of the Nigerian local dog: implications in veterinary oral and maxillo-facial anaesthesiology of the dolichocephalic canine breed. Int. J. Morphol., 32(2):738-743, 2014.

SUMMARY: There has been a recent increase in the use of trained dogs in animal-assisted therapy programmes. This morphological study uses the Nigerian local dog as a prototype dolichocephalic to determine rostrofacial parameters which are of clinical and anesthesiological importance in veterinary oral surgery and intervention. Sixteen Nigerian local dog skulls of both sexes (seven males and nine females) were used. The females were observed to have higher values for most of the parameters measured. Statistically significant difference $(\mathrm{P}<0.05)$ was only observed in one parameter, distance between the mandibular foramen and the caudal border of the mandible, with the female value being higher. The length of the mandible from the most rostral point of the dental bone to the most caudal projection of the coronoid process (MDL-1) showed a positive correlation to the parameters depicting height, width and length of the mandible. Results obtained from this study will find application in veterinary comparative anatomy and in clinical application in oral and maxillofacial surgery and anaesthesia, especially in regions where the dental x-ray is not readily available.
\end{abstract}

KEY WORDS: Nigerian local dog; Rostrofacial indices; Regional anaesthesia; Skull; Morphology.

\section{INTRODUCTION}

Dogs are companion animals that when trained, have been reputed to be extremely useful in animal-assisted therapy programmes in health facilities, for example, psychotherapy and physical rehabilitation (Voelker, 1995). The Nigerian local dogs (NLD) are a breed indigenous to Nigeria; they are popularly referred to as 'mongrels' by indigenes. They are long-headed (dolichocephalic) dogs, domesticated, with their feeding pattern being majorly omnivorous as a consequence of the high level of domestication (Igado, 2011). The present population of NLD is estimated to be about 4.5 million. In the rural areas, they are used locally for hunting, while in the metropolitan cities they are useful as guard dogs and also pets. In recent years, there has been an increase in the acquisition of this breed of dog probably due to the fact that they are more resistant to some haemo-parasites (e.g. babesiosis and trypanosomosis) that constantly plague the exotic breeds (Olayemi et al., 2009)

Regional nerve blocks serve as a practical means of peri- and post-operative analgesia, as an adjunct to general anaesthesia for painful oral procedures in companion animals. They are quick and easy to administer and have been reported to have low incidence of complications. When administered as post-operative analgesia, it allows less aggressive systemic pain management during recovery (Beckman \& Legendre, 2002).

This study forms part of an ongoing study on the cranial or skull morphometry of the Nigerian Local (or indigenous) dog.

\section{MATERIAL AND METHOD}

Ethical approval for this study was obtained from the Ethical Committee of the Faculty of Veterinary Medicine, University of Ibadan, Nigeria, Ethical code number 'ethic/ 05/11/01'. All procedures followed the Guide for the care and use of experimental animals (Faculty of Veterinary Medicine, University of Ibadan, Nigeria). 
A total of sixteen clinically healthy adult Nigerian local dogs (7 males, 9 females) were used for this study. All animals were aged 2 years or more. Age was obtained from vendors and confirmed using the dental formula according to Dyce et al. (2002). The animals were weighed with a standard bathroom scale and euthanized by intravenous injection of pentobarbitone. The heads were severed at the atlantooccipital junction.

The severed heads were skinned and de-fleshed with a scalpel blade as much as possible, and thereafter subjected to the hot water maceration technique as previously described by Igado. Briefly, the heads were tagged and labelled for ease of identification, then placed in water containing polycarboxylate and anionic surfactant (detergent), with soap chips (sodium carbonate), heated to $100^{\circ} \mathrm{C}$ for one hour. Further removal of muscle and ligament was done, and the skulls were rinsed with clean water and thereafter transferred to a water solution containing detergent, $0.3 \%$ sodium hypochlorite and $6 \%$ hydrogen peroxide solution for 18 hours. The skulls were again rinsed in clean water and then left in the sun to dry. A total of 24 parameters were measured on each skull. Some of the parameters measured were adapted from Endo et al. (2002) and Olopade \& Okandeji (2010). Measurements were determined with the aid of vernier callipers, centimetre rule, mathematical dividers and compass. The parameters measured and their landmarks are described below and illustrated in figures 1-7. All measurements were recorded in centimeters $(\mathrm{cm})$.

Definitions of measured parameters and their landmarks. 1. Distance between the most medial points of the most rostral left and right mental foramina (RMF)

2. Distance between the alveolar border of the 3rd lower incisor and the most ventral point of the most rostral mental foramen (IRMF)

3. Length along a horizontal line, from the ventral limit of the mandibular foramen to the caudal border of the mandible (MFCB)

4. Length, along a vertical line, from the ventral limit of the middle mental foramen, to the ventral border of the mandibular foramen (MFMF)

5. Length, along a vertical line, from the ventral limit of the mandibular foramen, to the base of the mandible (MFMB)

6. Length along a vertical line, from the ventral limit of the mandibular foramen, to the most dorsal aspect of the coronoid process (MFCP)

7. Length of the lower jaw from the most rostral point of the dental bone to the most caudal projection of the coronoid process (MDL-1)

8. Length of the lower jaw from the most rostral point of the dental bone to the most caudal projection of the mandibular condyle (condylar process) (MDL-2)

9. Length of the lower jaw, from the most rostral point of the dental bone to the most caudal projection of the angular process (MDL-3)

10. Height of the mandibular body between the mid-point of premolar 1 and 2 and the mandibular base (HMP)

11. Thickness of mandible at molar 1 (TM-1)

12. Thickness of the mandible, between the medial and lateral parts of the mandible, caudal to the last molar tooth (TR)

13. Length of the mandible between the cranial and caudal angles (RAM). This was measured as the distance from immediately caudal to the last molar tooth (cranial angle), to the ventral aspect of the angular process (caudal angle). 14. Distance from the rostral tip of the nasal bone to the rostral tip of the incisive bone (NIL)

15. Distance between the caudal limit/rim of the infraorbital foramen and the medial canthus of the orbit (IFMO)

16. Distance from the ventral limit of the infraorbital foramen to the alveolar border between the upper 3rd and 4th premolars (IFP).

17. Distance, along a horizontal line, between the caudal rim of the infraorbital foramen and the cranial tip of the facial crest (FCIF)

18. Distance, from the tip of the zygomatic process of the frontal bone to the caudal rim of the infra-orbital foramen (ZPIF).

19. Vertical Diameter of the infraorbital foramen (DIFv)

20. Horizontal Diameter of the infraorbital foramen (DIFh).

21. Height of the mandibular symphysis (HSPh)

22. Length of the mandibular symphysis (LSPh)

23. Distance between the two lower (mandibular) premolars, at the level of the 2 nd premolars, measured along the transverse plane (D2P)

24. Distance between the lower (mandibular) last molars, measured along the transverse plane (DLM)

Statistical Analysis. All data obtained were analysed using the Graph-pad version 4 software. Student's t-test was used to determine statistical significant differences between the male and female values, at significant level of $5 \%$.

\section{RESULTS}

Results are as presented in Tables I (as Mean \pm standard deviation) and II. In the linear measurements taken, statistically significant difference between male and female $(\mathrm{P}<0.05)$ was only observed in MFCB, with the females having higher values. Out of the 24 parameters measured, the males were observed to have higher values in only 3 parameters, DIFv, DIFh and D2P, although no statistically 


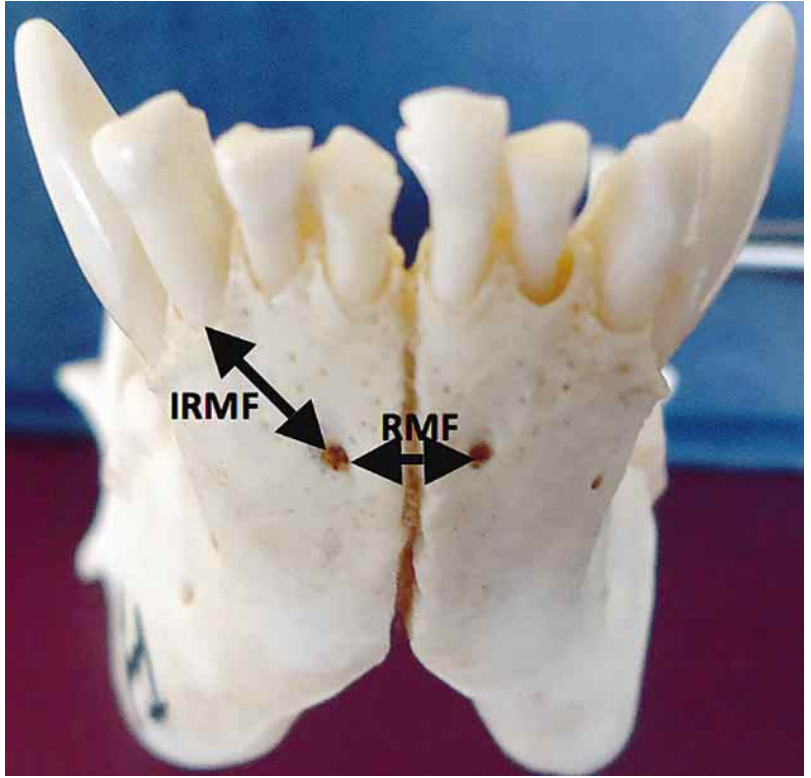

Fig. 1. Rostral view of the mandible of the NLD showing RMF and IRMF.

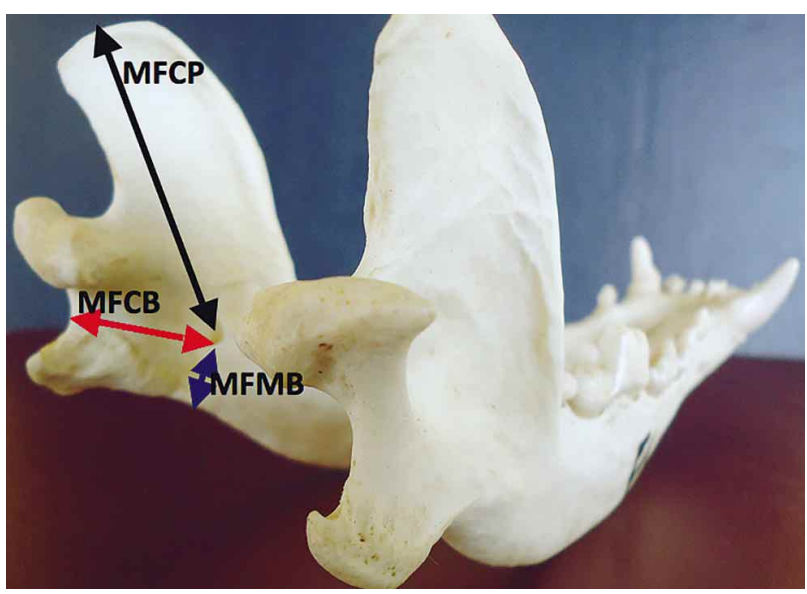

Fig. 2. Lateral view of the skull of the Nigerian local dog showing MFCB (red arrow), MFMB (blue arrow) and MFCP (longer black arrow).

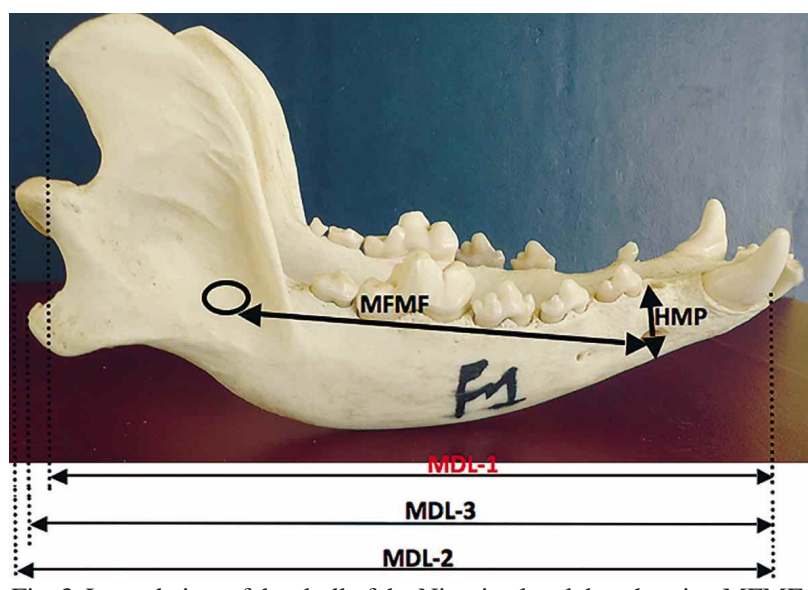

Fig. 3. Lateral view of the skull of the Nigerian local dog showing MFMF, MDL-1, MDL-2, MDL-3 and HMP. NOTE: the black circle depicts the location of the mandibular foramen.

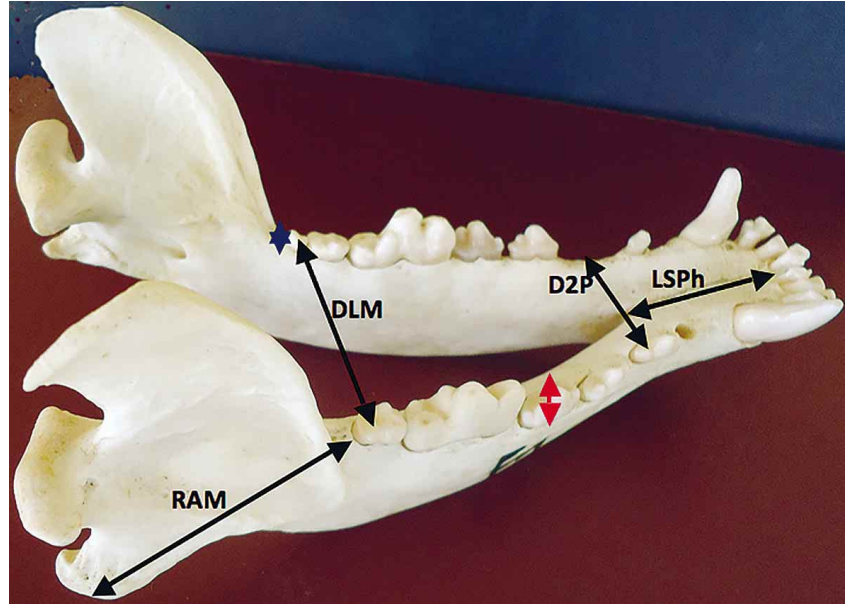

Fig. 4. Dorsal view of the skull of the NLD, showing RAM, TM-1 (red arrow), LSPh, D2P, TR (blue arrow) and DLM.

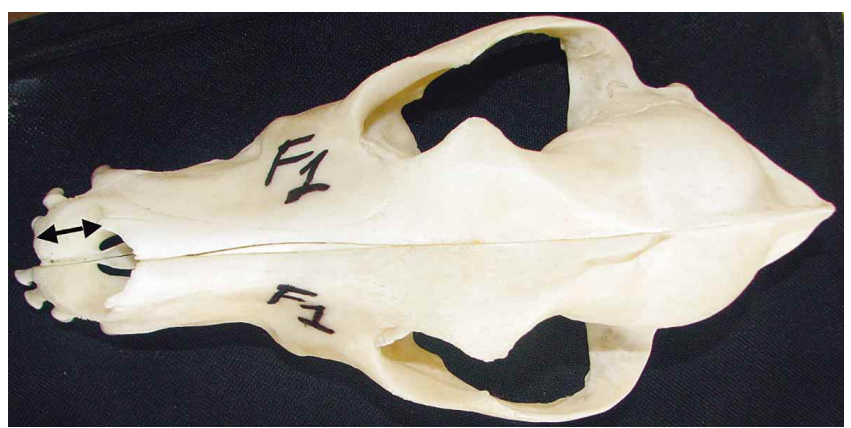

Fig. 5. Dorsal view of the skull of the NLD showing NIL

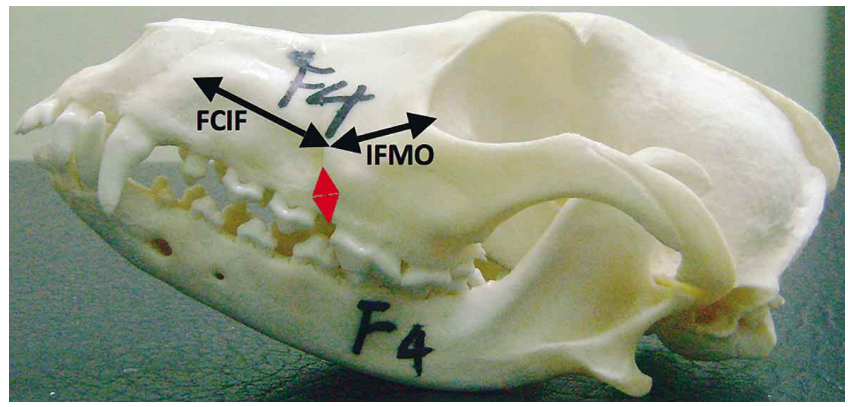

Fig. 6. Left lateral view of the skull of the NLD showing IFMO, IFP (red arrow) and FCIF.

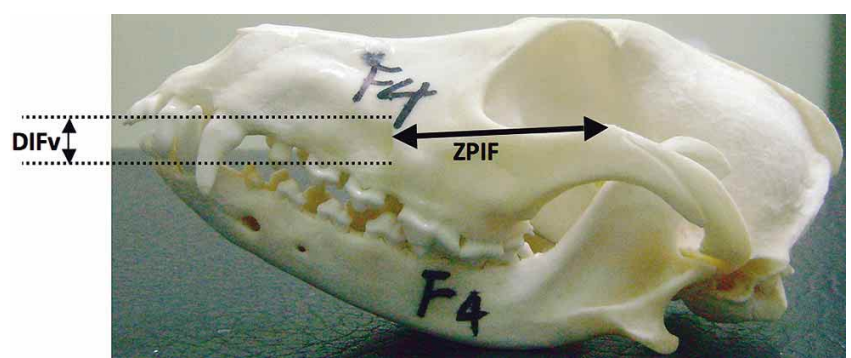

Fig. 7: Left lateral view of the skull of the NLD showing ZPIF and DIFv 
significant differences were observed $(\mathrm{P}>0.05)$. Values obtained for MDL-1, MDL-2, MDL-3, HMP, TM1 and TR were found to be higher in the females relative to the males (Table I), although no statistically significant differences were also observed $(\mathrm{P}>0.05)$.

In both sexes, the infraorbital foramen was observed to be located above the third premolar, with the ventral limit slanting slightly caudally to a region between the third and fourth premolar. The distance from the ventral limit of the rim of this foramen to the alveolar border between the 3rd and 4th premolar gave a value that was higher in females $(0.73 \pm 0.14 \mathrm{~cm})$ relative to the males $(0.66 \pm 0.15 \mathrm{~cm})$, although no statistically significant difference was observed $(\mathrm{P}>0.05)$. The value obtained for both male and female was $0.7 \pm 0.14 \mathrm{~cm}$. The vertical and horizontal diameter of the infraorbital foramen were very similar in both sexes $(0.61 \pm 0.08 \mathrm{~cm}$, male- $0.62 \pm 0.08 \mathrm{~cm}$, female- $0.6 \pm 0.08 \mathrm{~cm}$; $0.25 \pm 0.05 \mathrm{~cm}$, male- $0.26 \pm 0.06 \mathrm{~cm}$, female- $0.25 \pm 0.05 \mathrm{~cm}$ respectively) (Table I).

Using Pearson's correlation (at significant level of $5 \%, \mathrm{P}<0.05$ ), MDL-1 showed significant positive correlation to RMF, IRMF, MFCP, MDL-2, MDL-3, HMP, TR, RAM, NIL, IFP, FCIF, ZPIF, DIFv, LSPh and DLM $(\mathrm{r}=0.78,0.83$, $0.82,0.98,0.96,0.67,0.71,0.75,0.94,0.56,0.57,0.85,0.57$, 0.72 and 0.76 respectively), while RMF showed significant positive correlation to IRMF, MFCP, MDL-1, MDL-2, MDL3, HMP, TR, RAM, FCIF, ZPIF, LSPh and DLM $(r=0.70$, $0.77,0.78,0.77,0.75,0.75,0.66,0.68,0.68,0.72,0.78$ and 0.63 respectively) (Table II).
Table I. Indices obtained in the Nigerian local dog (values expressed in centimetres, $\mathrm{cm}$ ).

\begin{tabular}{ccccc}
\hline & Parameters & Total values & Male values & Female values \\
\cline { 2 - 5 } & $(\mathbf{c m})$ & $\mathbf{n = 1 6}$ & $\mathbf{n}=\mathbf{7}$ & $\mathbf{n = 9}$ \\
\hline 1 & RMF & $0.33 \pm 0.08$ & $0.28 \pm 0.05$ & $0.36 \pm 0.07$ \\
2 & IRMF & $0.45 \pm 0.12$ & $0.4 \pm 0.14$ & $0.48 \pm 0.10$ \\
3 & MFCB & $1.31 \pm 0.18$ & $1.18 \pm 0.11 *$ & $1.39 \pm 0.17 *$ \\
4 & MFMF & $7.45 \pm 0.64$ & $7.16 \pm 0.49$ & $7.64 \pm 0.68$ \\
5 & MFMB & $2.12 \pm 0.45$ & $1.9 \pm 0.4$ & $2.26 \pm 0.45$ \\
6 & MFCP & $3.86 \pm 0.49$ & $3.64 \pm 0.46$ & $4.0 \pm 0.49$ \\
7 & MDL-1 & $11.42 \pm 1.11$ & $10.98 \pm 0.94$ & $11.7 \pm 1.18$ \\
8 & MDL-2 & $11.91 \pm 1.05$ & $11.54 \pm 0.90$ & $12.14 \pm 1.13$ \\
9 & MDL-3 & $11.82 \pm 1.01$ & $11.5 \pm 0.97$ & $12.01 \pm 1.05$ \\
10 & HMP & $1.53 \pm 0.22$ & $1.42 \pm 0.24$ & $1.6 \pm 0.19$ \\
11 & TM1 & $1.19 \pm 0.37$ & $1.08 \pm 0.41$ & $1.26 \pm 0.35$ \\
12 & TR & $0.71 \pm 0.11$ & $0.66 \pm 0.06$ & $0.74 \pm 0.13$ \\
13 & RAM & $2.07 \pm 0.16$ & $2.04 \pm 0.18$ & $2.09 \pm 0.15$ \\
14 & NIL & $2.36 \pm 0.20$ & $2.33 \pm 0.15$ & $2.38 \pm 0.24$ \\
15 & IFMO & $2.02 \pm 0.34$ & $1.9 \pm 0.25$ & $2.1 \pm 0.38$ \\
16 & IFP & $0.7 \pm 0.14$ & $0.66 \pm 0.15$ & $0.73 \pm 0.14$ \\
17 & FCIF & $0.54 \pm 0.20$ & $0.42 \pm 0.08$ & $0.61 \pm 0.22$ \\
18 & ZPIF & $4.59 \pm 0.53$ & $4.34 \pm 0.50$ & $4.77 \pm 0.50$ \\
19 & DIFv & $0.61 \pm 0.08$ & $0.62 \pm 0.08$ & $0.6 \pm 0.08 \#$ \\
20 & DIFh & $0.25 \pm 0.05$ & $0.26 \pm 0.06$ & $0.25 \pm 0.05 \#$ \\
21 & HSPh & $0.99 \pm 0.14$ & $0.93 \pm 0.12$ & $1.02 \pm 0.14$ \\
22 & LSPh & $1.86 \pm 0.25$ & $1.78 \pm 0.24$ & $1.91 \pm 0.25$ \\
23 & D2P & $1.77 \pm 0.30$ & $1.90 \pm 0.24$ & $1.70 \pm 0.31 \#$ \\
24 & DLM & $3.33 \pm 0.27$ & $3.28 \pm 0.28$ & $3.36 \pm 0.27$ \\
\hline
\end{tabular}

Note: *Indicates values showing statistically significant differences $(\mathrm{P}<0.05)$ between male and female values. \# Indicates parameters which had higher values in males, although no statistically significant differences were observed $(\mathrm{P}>0.05)$.
Table II. Pearson's correlation values of MDL-1 and RMF with other parameters.

\begin{tabular}{lll}
\hline & MDL-1 & RMF \\
\hline RMF & 0.78 & - \\
IRMF & 0.83 & 0.70 \\
MFMCB & 0.23 & 0.07 \\
MFMF & 0.55 & 0.48 \\
MFMB & 0.28 & 0.36 \\
MFCP & 0.82 & 0.77 \\
MDL-1 & - & 0.78 \\
MDL-2 & 0.98 & 0.77 \\
MDL-3 & 0.96 & 0.75 \\
HMP & 0.67 & 0.75 \\
TM1 & -0.20 & -0.15 \\
TR & 0.71 & 0.66 \\
RAM & 0.75 & 0.68 \\
NIL & 0.94 & 0.68 \\
IFMO & 0.48 & 0.42 \\
IFP & 0.60 & 0.55 \\
FCIF & 0.57 & 0.68 \\
ZPIF & 0.85 & 0.72 \\
DIFv & 0.57 & 0.54 \\
DIFh & 0.44 & 0.38 \\
HSPh & 0.27 & 0.40 \\
LSPh & 0.72 & 0.78 \\
D2P & 0.51 & 0.31 \\
DLM & 0.76 & 0.63 \\
\hline
\end{tabular}

\section{DISCUSSION}

The mean values obtained in this study were observed to be higher in the females (with the exception of DIFv, DIFh and $\mathrm{D} 2 \mathrm{P})$, and statistical significance $(\mathrm{P}<0.05)$ observed in only MFCB, showing that these females had longer and 
higher mandibles relative to the males. This is in consonance with what was previously observed in the swine (Olopade \& Okandeji) and armadillos (Squarcia et al., 2009).

Blocking of the infra-orbital nerve in the dog results in the desensitization of the upper lip, nose, roof of the nasal cavity and skin as far caudal as the infra-orbital foramen (Duke, 2000). The higher values recorded for the infraorbital foramen dimensions (DIFv and DIFh) in the males may imply a bigger infra-orbital nerve, which is easier to access and palpate in the live animal, even though no statistically significant differences were observed $(\mathrm{P}>0.05)$. This disparity in mandibular length and infra-orbital foramen dimensions between the genders may serve as important landmarks or variables to distinguish the skulls of the sexes. The distance between the infra-orbital foramen and the medial canthus, premolars, facial crest and the zygomatic process recorded no statistically significant differences between the genders $(\mathrm{P}>0.05)$. The position of the infraorbital foramen as described earlier was found to be consistent with previous diagrammatic reports in other dolichocephalics (Dyce et al.; Beckman \& Legendre). This observation may prove useful in locating the infra-orbital nerve for the purpose of desensitization of the areas the nerve supplies and also in removal of the cheek teeth. The similarities in the vertical and horizontal diameters of the infraorbital foramen between the sexes may imply that the size of the nerve in both sexes is very similar or there exists no appreciable difference in the nerve size.

Three mental foramina were observed on either side (left and right sides) as previously reported by Beckman \& Legendre and Dyce $e t$ al., with the middle foramen being the largest and the most rostral being the smallest. Blocking of the mental nerve results in desensitization of the bone, teeth and soft tissue rostral to the second premolar on the side infiltrated. The location of the mental nerve varies slightly with the breed, size and species of the patient. This foramen is ideally located in the live animal with the aid of dental radiography (Beckman \& Legendre). In the NLD, the middle foramen was situated in the region below the 1st and 2nd premolars, consistently in both genders.

The mandibular nerve block, also known as the inferior alveolar nerve block, can be achieved intra-orally and extra-orally. Blocking this nerve affects the mandibular bone, teeth, soft tissue, and tongue on the infiltrated side (Beckman \& Legendre). Accessing this foramen and nerve requires more skill and expertise relative to the infra-orbital and mental nerves. Using the calculated distances of the foramen to the caudal border of the mandible, mental foramen, base of mandible and the coronoid process (MFCB, MFMF, MFMB, MFCP respectively) will aid accessibility of this nerve. The distances of the mandibular foramen to the base of the mandible and that from the caudal border of the mandible to the ventral limit of the mandibular foramen are clinically important landmarks that will aid regional anaesthesia of this nerve (Hall et al., 2000). The values for the distances from the mandibular foramen (MFCB, MFMF, MFMB, MFCP) observed in this study were consistently greater in the females, although statistically significant difference $(\mathrm{P}<0.05)$ was only observed in MFCB (Table I). This greater value in females is similar to what was obtained in pigs when the distances between the mandibular foramen and the caudal border of the mandible and the base of the mandible were measured (Olopade \& Okandeji).

The strongly positive correlation displayed between MDL-1 and the other parameters imply that this parameter may probably be used to assess size and age in age-related studies, as an increase in MDL-1 resulted in a proportionate increase in parameters measuring height and thickness of the mandibles.

Regional nerve block is a convenient and easy way to induce analgesia and few materials are required to perform regional nerve blocks. In addition, the mental, infra-orbital and mandibular nerves can be blocked alone or in combination to provide the needed analgesia to any region in the oral cavity (Beckman \& Legendre) and the maxillafacial region.

In conclusion, the results obtained from this study may find application in the area of comparative anatomy and pathology, archaeology, and will also come in useful in regions like the developing countries, or situations where the dental $x$-ray machines are not readily available in veterinary surgical cases.

\section{ACKNOWLEDGEMENTS}

The author gratefully acknowledges the technical assistance of Dr. O.K. Ekeolu, Mr. A.W. Ramoni and Mrs. E.B. Adeyemo, all of the Department of Veterinary Anatomy, University of Ibadan.

IGADO, O. O. Índice rostrofacial del perro local nigeriano: implicancias en anestesiología oral y maxilofacial veterinaria de la raza canina dolicocéfala. Int. J. Morphol., 32(2):738-743, 2014.

RESUMEN: Se ha observado un reciente aumento en el uso de perros entrenados en los programas de terapia asistida con animales. Este estudio morfológico utiliza el perro local de Nigeria como prototipo dolicocéfalo para determinar los parámetros 
rostrofaciales, de importancia clínica en la intervención quirúrgica y asistencia anestesiológica oral en veterinaria. Se utilizaron 16 cráneos de perros de ambos sexos (siete machos y nueve hembras). Se observó que las hembras tenían valores más altos para la mayoría de los parámetros medidos. Una diferencia estadísticamente significativa $(\mathrm{P}<0,05)$ sólo se observó en un parámetro, la distancia entre el foramen mandibular y el margen caudal de la mandíbula, donde las hembras registraron el valor más alto. La longitud de la mandíbula desde el punto del hueso dental más rostral, a la proyección caudal del proceso coronoides mandibular mostró una correlación positiva para los parámetros de altura, ancho y longitud mandibular. Los resultados obtenidos pueden ser aplicados en anatomía veterinaria, así como en clínica para cirugía oral, maxilofacial y el uso de anestesia, especialmente en lugares o situaciones donde la radiografía dental no siempre está al alcance.

PALABRAS CLAVE: Perro local nigeriano; Índice rostrofacial; Anestesia regional; Craneo; Morfología.

\section{REFERENCES}

Beckman, B. W. \& Legendre L. Regional nerve blocks for oral surgery in companion animals. Comp. Cont. Ed. Prac. Vet., 24(6):439-44, 2002.

Duke, T. Local and regional anesthetic and analgesic techniques in the dog and cat: Part II, infiltration and nerve blocks. Can. Vet. J., 41(12):949-52, 2000.

Dyce, K. M.; Sack, W. O. \& Wensing, C. J. G. Textbook of Veterinary Anatomy. 3rd ed. Philadelphia, Saunders, 2002.

Endo, H.; Hayashi, Y.; Yamazaki, K.; Motokawa, M.; Pei, J. K.; Lin, L.; Chou, C. \& Oshida, T. Geographical Variation of Mandible Size and Shape in the Wild Pig (Sus scrofa) from Taiwan and Japan. Zool. Stud., 41(4):452-60, 2002.

Hall, L. W.; Clarke, K. W. \& Trim, C. M. Wright's Veterinary Anaesthesia and Analgesia.10 ${ }^{\text {th }}$ ed. London, ELBS and BaillièreTindall, 2000.

Igado, O. O. Neurometrics and neurocraniometry of the Nigerian local dog (Canis lupus familiaris). J. Vet. Anat., 4(2):99-109, 2011.

Olayemi, F. O.; Azeez, I. O.; Ogunyemi, A. \& Ighagbon, F. O. Study on erythtocyte values of the nigerian indigenous dog. Folia Vet., 53(2):65-7, 2009.

Olopade, J .O. \& Okandeji, M. E. A Study of Some Rostrofacial Indices Related to Regional Anaesthesia of the Porcine: Implications as an Animal Model for Dental Research. Niger. J. Physiol. Sci., 25(2):159-64, 2010.

Squarcia, S. M.; Sidorkewicj, N. S.; Camina, R. \& Casanave, E. B. Sexual dimorphism in the mandible of the armadillo
Chaetophractus villosus (Desmarest, 1804) (Dasypodidae) from northern Patagonia, Argentina. Braz. J. Biol., 69(2):34752,2009 .

Voelker, R. Puppy love can be therapeutic, too. JAMA, 274(24):1897-9, 1995.

Correspondence to:

Dr. Olumayowa O. Igado

Comparative Anatomy, Neuroscience and

Environmental Toxicology Unit,

Department of Veterinary Anatomy

University of Ibadan

NIGERIA

Email: mayowaigado@yahoo.com

Received: 04-04-2013

Accepted: 08-01-2014 